\title{
Assessment of Building-Integrated Green Technologies: A Review and Case Study on Applications of Multi-Criteria Decision Making (MCDM) Method
}

\author{
Jin $\mathrm{Si}{ }^{*}$, Ljiljana Marjanovic-Halburd ${ }^{1}$, Fuzhan Nasiri², Sarah Bell ${ }^{3}$ \\ 1 Institute for Environmental Design and Engineering, the Bartlett, University College London, Central \\ House, 14 Upper Woburn Place, London WC1H ONN \\ ${ }^{2}$ Department of Building, Civil, and Environmental Engineering Concordia University, Montreal, QC, \\ Canada, H3G 2W1 \\ ${ }^{3}$ Department of Civil, Environmental \& Geomatic Engineering, University College London, Gower Street, \\ London, WC1E 6BT
}

\begin{abstract}
Retrofitting existing buildings with appropriate green technologies is an important element of strategies to mitigate climate change. The selection of green technologies can be a challenging task, where multiple criteria exist and interrelate. However, it is still common for decisions to be based on a single criterion, such as energy efficiency or cost. This paper aims to evaluate the application of Multi-Criteria Decision Making (MCDM) methods to the selection of green technologies for retrofitting to existing buildings. The paper begins with a review of MCDM methods and the use of these techniques for selecting technologies to retrofit existing buildings. The applicability of Analytical Hierarchy Process (AHP), a widely used MCDM method, is demonstrated through a case study of a building that is part of a university estate. The findings show that AHP can help to formulate the problem, and facilitate the assessment and ranking of retrofitting measures when multiple criteria are jointly considered. We have shown that by considering environmental and economic criteria, control technologies such as variable speed drives in air handling units, rank most highly in this case. It has also been suggested that social criteria, such as occupant satisfaction, should also be considered as part of the sustainability agenda, although this can be more difficult to achieve than consideration of environmental and economic criteria, which are more readily characterised using quantitative data. We conclude by proposing an integrated green technology assessment and selection framework, which is applicable to existing buildings.
\end{abstract}

Key words: Non-domestic buildings; Building-Integrated green technologies; Multi-Criteria Decision Making (MCDM) methods; Analytical Hierarchy Process (AHP); Climate change mitigation

\section{Introduction}

The United Nations Environment Programme (UNEP) has estimated that buildings contribute up to $30 \%$ of global annual greenhouse gas (GHG) emissions and consume up to $40 \%$ of all primary energy (UNEP-SBCI, 2009). The building sector is recognised as the

* Corresponding author. Tel: +44(0)7746300209

E-mail address: j.si.12@ucl.ac.uk 
largest consumer of primary energy, compared to other major sectors such as industry and transportation (Pérez-Lombard et al. 2008; Butler, 2008; Saidur, 2009). Cost effective reductions in GHG emissions and energy savings of more than $30 \%$ are possible in many countries (UNEP-SBCl, 2009). As such, the building sector should be a high priority in local, regional, and global climate change mitigation strategies.

Energy efficiency improvement in buildings is one of most effective measures to reduce carbon emissions, especially as many buildings are characterised by poor energy performance (Saidur, 2009; Spyropoulos and Balaras, 2011). Energy efficiency can be reduced significantly through retrofitting existing buildings with new technologies (Ardente et al. 2011; Chidiac et al. 2011). Given relatively low rates of replacement of existing buildings by new buildings, retrofitting the existing building stock has been identified as having greater potential to improve energy efficiency and reduce GHG emissions than improving standards of new buildings (Norris and Shiels, 2004; Roberts, 2008; Energy Efficiency Directive, 2012).

The performance of existing buildings can be improved using a range of retrofit options, including energy reduction measures and low carbon technologies. Energy reduction measures can include draught proofing measures, improvement in wall insulation and replacement of windows to minimise heat gains. Other measures, such as enhancing natural ventilation and daylight, can further reduce energy consumption (Roberts, 2008). A green roof can also be considered as an energy reduction measure suitable for retrofit if it provides insulation and cooling due to evapotranspiration, and can been supported by the existing building structure (Castleton et al. 2010). Low carbon technologies can include solar systems, wind turbines, biomass boilers and combined heat and power systems, which have lower GHG emissions than conventional energy supply systems.

However, the selection of retrofit measures for existing buildings is a complex task. The success of retrofitting is subject to many uncertainties, including occupant behavior, government policy changes and climate volatilities, all of which directly affect the selection and performance of technologies. Other challenges may include financial limitations, long payback periods, and interruptions to operations. At the technical level, different retrofit measures may have different impacts on associated building sub-systems (Ma et al. 2012). With the rise of sustainability agenda in building sector, it is essential for the decision makers to consider sustainability criteria, which address environmental, economic and social performance. The interdependencies and conflicting nature between these criteria are well recognised. The qualitative and quantitative nature of different criteria also increases the complexity of analysis. Dealing with these uncertainties and system interactions is a considerable technical challenge in any sustainable building retrofit project.

The current decision-making process surrounding building retrofit is commonly based on a single economic criterion, such as a cost-benefit ratio obtained through a financial performance analysis (Nelms et al. 2005). Faced with lack of established practices in use of decision making tools, designers and building managers are more likely to turn to intuition (Pan et al. 2012). Multi Criteria Decision Making (MCDM) methods have been proposed to assist with the selection of green technologies for buildings (Dangana et al. 2013). MCDM 
methods can deconstruct the problem of decision making into discrete steps, compare the relative importance of criteria and select the optimal alternative using rigorous mathematical models. These methods can clarify the interrelations between criteria and minimise the subjectivity of the selection (Linkov and Moberg, 2012). MCDM methods have been used to support design decisions for low carbon buildings (Dawood et al. 2013) and in evaluation of climate change mitigation policy instruments (Konidari and Mavrakis, 2007). There is a need to investigate the effectives of MCDM methods to support decisions about technology selection when retrofitting existing buildings.

The aim of this paper is to explore the application of MCDM methods in technology selection for retrofitting existing buildings. Section 2 presents state-of-the-art in green technology selection and reviews the MCDM family of methods. It also provides a discussion on the characteristics of the MCDM methods employed into assessment and selection of alternative green technologies considered for integration into existing building. Section 3 presents a case study. The paper concludes with the merits and limitations of MCDM in the context of building retrofitting, and outlines avenues for future research.

\section{Assessment of green technologies for building integration and retrofit}

\subsection{Decision making with multiple criteria}

Robust selection of green technologies takes account of multiple criteria. These criteria can be technical, such as capacity requirements, spatial requirements, reliability and flexibility; economic, such as capital cost, operating cost and maintenance cost; environmental such as carbon reduction and energy saving potential; and social such as occupant health and safety and employment creation. These criteria can influence the decision makers' goal and reflected as different priorities, which may be represented as weightings in decision support systems.

MCDM methods provide mathematical models to weight criteria, score alternatives and synthesize the final results. The process of decision making with several criteria is characterised by following phases (Gore et al. 1992):

- objective identification;

- criteria development;

- alternative generation, evaluation and selection;

- implementation and monitoring.

\section{Criteria development and information collection}

The principles of good criteria selection are: a systematic approach; consistency; independency; measurability; and comparability ( $\mathrm{Ye}$ et al. 2006). The criteria are normally organised in a hierarchy from general to detailed. For each level, criteria should be mutually exclusive but inclusive within the upper level of criteria. However, this rule is not easy to comply with when dealing with sustainability criteria. The economic, environmental, social and technical criteria are interrelated, and if not organised in a clear way, the information can 
overlap, leading to double-counting in the analysis. For instance, boiler efficiency can be structured under technical criteria, but can also be placed under cost, environmental or social criteria, since boiler efficiency will impact GHG emissions, which influence the environment and human welfare, and will reduce fuel costs. Criteria structuring or specification of the criteria implications at the initial stage can help to define a hierarchy with clear relationships.

The criteria can be collected from a literature review, surveys, interviews and workshops with stakeholders, or the combination of these methods (Pan et al. 2012). A long list of criteria might be collected from expert consultation without much knowledge about interrelationships that could exist among these criteria. However, there are methods available to reduce the number of decision criteria to a representative list. The most common methods are the Delphi, the least mean square (LMS), the minmax deviation and the correlation coefficient method. The Dephi method is based on several rounds of discussions or surveys amongst a group of experts with the aim converging towards a representative set of criteria (Rowe and Wright, 2001). The LMS method is used to eliminate the criteria with similar performance across the alternatives (Guo, 2007). The minmax deviation method is to remove the criteria with less deviation of performance values (Ye et al. 2006). The correlation coefficient method is to analyse the interrelationship between criteria (Papadatos and Xifara, 2013). If the correlation coefficient between two criteria is close to 1 , the two criteria are closely related, and therefore one of them can be removed.

\section{Criteria weighting}

After establishing the set of criteria, weights must be assigned to reflect on their relative importance. Available weighting methods can be classified into two categories: equal weights method and rank-order weighting method. The equal weights method does not require the decision makers' preferences. The rank-order weighting methods are designed to compare the relative importance of the criteria. These methods include subjective weighting, objective weighting and combination weighting methods. Subjective weighting methods only consider the opinions of decision makers, while objective weighting methods decide the weights based on the criteria value data.

Subjective weighting methods include Simple Multi-Attribute Rating Technique (SMART), swing and pair-wise comparison methods such as AHP. In SMART, decision makers assign 10 points to the least important criteria and then add points up to 100 when the importance increases (Zardari et al. 2015). Swing method is asking decision makes to assign 100 points to the criteria with the highest expectation of dramatic improvements. Fewer points are then given to the next candidate. The Pair-wise comparison method is comparing the importance between two criteria (Linkow and Moberg, 2012). AHP is one type of pair-wise comparison with 9-scale for a relative importance comparison.

The objective weighting methods include the Entropy method, the Technique for Order Preference by Similarity to Ideal Solution (TOPSIS) method, as well as the Vertical and Horizontal method. These methods are characterised by mathematical models and are described in Løken (2007). In addition to these subjective and objective weighting methods, Wang et al (2009) has suggested combining subjective weighting and objective weighting. 


\section{Alternatives scoring}

With the criteria and their weights available, the performance of alternatives can be scored. The performance of information may be available as quantitative or qualitative data. Normalisation of quantitative data facilitates comparison of criteria with different dimensions and distribution. Qualitative information should be converted into numerical values using specific utility functions. In the case of the linear utility function, the interpolation method can be used to assign values to qualitative performance after establishing boundary and baseline values (Collier et al. 2013). When the scoring functions of alternatives are not easy to develop, AHP can be utilised as a pair-wise comparison method for the derivation of relative scores.

\section{Synthesis and selection}

Synthesis is the process of choosing the right model to integrate the scoring information and identify the best decision alternative. There are several methods available such as Multi-Attribute Utility Theory (MAUT), AHP and Outranking. An overview of these methods is shown in Table 1.

Table 1 The overview of MCDM methods

(Pohekar and Ramachandran, 2004; Linkov and Ramadan, 2004)

\begin{tabular}{ccc}
\hline \multicolumn{2}{c}{ Method } & Main characteristics \\
\hline $\begin{array}{c}\text { Multi-Attribute } \\
\text { Utility Theory } \\
\text { or }\end{array}$ & $\begin{array}{c}\text { Weighted sum } \\
\text { model(WSM) }\end{array}$ & $\begin{array}{c}\text { Good for single dimensional problems, but not always } \\
\text { suitable for multi-dimensional MCDM problems }\end{array}$ \\
$\begin{array}{c}\text { Multi-Attribute } \\
\text { Value Theory } \\
\text { (MAUT) }\end{array}$ & $\begin{array}{c}\text { Weighted product } \\
\text { model(WPM) }\end{array}$ & $\begin{array}{c}\text { Can be applied to single and multi- dimensional } \\
\text { problems, but is not suitable qualitative criteria } \\
\text { assessment. }\end{array}$
\end{tabular}

Decomposes a MCDM problem into a hierarchy of criteria and sub-criteria to be recomposed Analytical Hierarchy systematically to generate the rankings of decision Process(AHP) alternatives. The identification of criteria weights is challenging and is mostly influenced by decision makers' judgments and preferences.

\begin{tabular}{ccc}
\hline & PROMETHEE & \\
\cline { 2 - 2 } Outranking & ELECTRE & $\begin{array}{c}\text { Applicable to decision problems that involve few } \\
\text { criteria with a large number of alternatives. }\end{array}$ \\
\cline { 2 - 2 } & TOPSIS
\end{tabular}

MAUT methods include the Weighted Sum Model (WSM) and the Weighted Product Model (WPM). The difference between these two models is that WSM uses addition in the 
calculation while WPM uses multiplication. AHP is one type of WSM, adding all the scores of alternative performance multiplied by the criteria weights. Outranking methods attempt to order alternatives by identifying the one that outperforms or dominates the other. The methods are based on the principle that a disadvantage on a particular criterion might be compensated by outperforming with respect to other criteria (Pirlot, 1997).

Because multiple synthesis methods may lead to different ranking results, an aggregation method can be used to assess which method is the best. The aggregation methods are voting methods and mathematical aggregation methods. The latter includes both the hard and the soft aggregation method, differing from each other on whether the preference of decision makers is included or not (Wang et al. 2009).

\section{AHP method overview}

AHP is one of widely used MCDM methods, which can consider qualitative and quantitative criteria simultaneously. The method has three steps:

1. structuring the hierarchy between criteria and alternatives;

2. producing pair-wise comparison matrix;

3. calculating weight values of criteria and scores of alternative performance.

When structuring the hierarchy, the overall objective is on the top, followed by less important criteria. All of the criteria can be satisfied, achieved by different alternatives. To be able to rank these alternatives against criteria of different importance, individual weighting factors must be assigned. That requires creation of a pair-wise comparison matrix. Alternatives are compared in pairs, and the results are organised into a scale of 1-9 from equally important (value of 1) to extremely most important (value of 9). (Mafakheri et al. 2007).

Pairwise comparisons are performed between the criteria or sub-criteria marking out their relative importance (preferability). Each result of the pairwise comparisons is divided by the sum of the column that it belongs to. Elements of the same row are added and the sum is divided by the number of criteria of sub-criteria. Therefore, each element of these matrixes is normalized, producing weight coefficients. This procedure is followed for all levels (Konidari and Mavrakis, 2007).

A pairwise comparison matrix is shown as $[A]$ in equation (1):

$$
[\mathrm{A}]=\left[\begin{array}{cccc}
a_{11} & a_{12} & \cdots & a_{1 n} \\
a_{21} & a_{22} & \cdots & a_{2 n} \\
\vdots & \vdots & \ddots & \vdots \\
a_{n 1} & a_{n 2} & \cdots & a_{n n}
\end{array}\right]=\left[\begin{array}{cccc}
c_{1} / c_{1} & c_{1} / c_{2} & \cdots & c_{1} / c_{n} \\
c_{2} / c_{1} & c_{2} / c_{2} & \cdots & c_{2} / c_{n} \\
\vdots & \vdots & \ddots & \vdots \\
c_{n} / c_{1} & c_{n} / c_{1} & \cdots & c_{n} / c_{n}
\end{array}\right]
$$

In the above matrix, $a_{i j}$ is a pair-wise comparison between technology $c_{i}$ and $c_{j}$ with respect to the criteria. In this sense, we have a pair-wise comparison matrix for each decision criteria containing the associated pairwise comparison of alternatives according to decision makers' preferences.

If matrix $[\mathrm{A}]$ satisfies the cardinal consistency property of $a_{i j} a_{j k}=a_{i k}$, it is referred to as reciprocal. For a reciprocal matrix $[A]$, we have the equation (2): 


$$
[\mathrm{A}][w]=\lambda_{\max }[w],
$$

where $\lambda_{\max }$ denotes the largest eigenvalue of $[\mathrm{A}]$, and $[w]$ is the weight vector that corresponds to decision alternatives. Given the value of $\lambda_{\max }$, we can check the consistency of decision makers' judgments (preferences) to make sure that the expressed judgments are consistent across each matrix. The consistency index (C.I.) can be computed using the equation (3), where $n$ is the size dimension of the matrix.

$$
\text { C.I. }=\frac{\lambda_{\max }-\mathrm{n}}{\mathrm{n}-1}
$$

In order to interpret the C.I. value of a particular matrix, a ratio called C.R. is calculated:

$$
\text { C.R. }=\frac{\text { C.I. }}{\text { R.I. }}
$$

where the random Index (R.I.) is the average C.I. value of a large sample of randomly generated reciprocal matrices (Satty, 2000). R.I. can have receives the following values; 0 for a $2 \times 2$ matrix, 0.58 for $3 \times 3,0.90$ for $4 \times 4,1.12$ for $5 \times 5,1.24$ for $6 \times 6,1.32$ for $7 \times 7,1.41$ for $8 \times 8$ and 1.45 for $9 \times 9$. If C.R. $<0.1$, the consistency is accepted; if C.R. $\geqslant 0.1$, the matrix is not consistent and the judgments should be reassessed.

\subsection{Green technology selection and assessment}

Mohsen and Akash (1997) applied the AHP method as part of a cost-benefit analysis of different domestic heating systems for Jordan. They compared a domestic solar water heating systems with other heating systems, including an electric heating system, central heating system, kerosene heater and LPG heater. The authors used AHP proposed by Satty (1990) to develop separate hierarchies for benefit and cost assessments. The integrated cost-to-benefit ratio was used and the solar water heating system was identified as the optimal system. The weights in this paper were suggested for a city-scale case without further details on how criteria weights were identified. Consequently, the weights should be adjusted if the model is used at building scale.

Wang et al. (2009) assessed and compared CHP systems including industry and household systems using the Grey Relational Analysis (GRA) method. GRA is one of the MCDM methods to address issues with complex interrelationships between criteria. In this study, the authors highlighted the importance of criteria weights accuracy. The combination weighting method was used to balance the subjectivity of stakeholders' preferences and the objectivity of actual data.

Sheikh and Kocaoglu (2011) conducted a comprehensive literature review of solar photovoltaic technology assessment. They found that very little existing research considered social, technological, economic, environmental and political factors simultaneously, and almost all lack the capacity for practical operation. Sheikh et al. (2011) then established the criteria from the perspectives of Social, Technological, Economic, Environmental and Political (STEEP) for renewable technologies, especially for solar PV at the regional scale. They took the integrated approach of the literature review and expert consultation to develop the criteria. 
Weights values were obtained using questionnaires. Again, the criteria are designed for community scale and thus are not applicable to individual buildings.

Collier et al. (2013) employed the Multi-Attribute Value Theory (MAVT) method to select the best roofing technologies among reflective, vegetated, and solar roofs. Based on a review of existing research on roofing technology, they found the existing technology selection criteria are non-comprehensive. They provided a list of comprehensive criteria with respect to various economic, social and environmental aspects, with a particular emphasis on social criteria such as research, education, recreation, aesthetics and innovation values. For these social criteria, the authors assigned numerical values to qualitative responses. For example, the responses such as "strongly agree", "somewhat agree", "neutral", "somewhat disagree" and "strongly disagree" have been assigned numerical values within predefined numerical interval (for example, -1 to 1 ). A sensitivity analysis was conducted to evaluate the impact of weights on the final outcome.

Nelms et al. (2005) developed a comprehensive framework for green technology assessment. They proposed a multi-dimensional conceptual model and six-phase screening approach for green technology selection. The conceptual model is constructed in three dimensions: building systems and components as one dimension ( $x$-axis), project life cycle as the other (y-axis), and performance measures as the third dimension (z-axis). The conceptual model reflects the interaction of technology performance and its impacts on other building systems over the project life cycle. The procedural technology screening process includes six phases:

1) Preliminary review on performance measures;

2) Impact assessment on building components;

3) Technical performance assessment;

4) Economic assessment;

5) Allocation of weight values;

6) Synthesizing the alternative ranks and decision.

The applicability of the framework was demonstrated through the assessment of the impact of integrating green roofs in two case study buildings.

Odhiambo and Wekesa (2010) suggested an approach for building technology assessment in the case of marginalised communities, where the poor urban population resides in informal shelters. They developed a conceptual model to demonstrate the interrelationships between environmental, engineering and socio-economic objectives. The criteria were identified through an extensive literature review and interviews with stakeholders. They recommend using the Simple Additive Weighting (SAW) scoring method. The method was used to score the alternatives according to the sum product of alternatives' attainments (i.e. their performance with respect to criteria) and criteria (Afshari et al. 2010).

Huang et al. (2012) performed a sustainability assessment of low carbon technologies for the building sector in China. They reviewed existing assessment methods at multiple levels (industry, project and technology). The Multi-Attributive Assessment of Clean Development 
Mechanism method (MATA-CDM method) at the project level was selected, as it was deemed capable of considering both sustainability and low carbon requirements. The MATA-CDM method is a method for the integration of multi-attribute utility analysis applied into Clean Development Mechanism projects (CDM projects). Using the multi-attribute utility method, the assessments associated with individual criterion are converted to a single utility value between -1 and 1. Positive values indicate the project has a positive performance where the benefits outperform the costs, and a negative value means a negative performance where costs exceed the benefits (Sutter, 2003). The results suggest that geothermal and solar PV technologies outperform electrical heating systems.

Ma et al. (2012) conducted a comprehensive review of crucial activities and elements influencing existing building retrofits. Based on this, a systematic approach to identifying, determining and implementation of optimal retrofit measures was proposed. The cost-benefit analysis and risk assessment were suggested to assess the potential retrofit technologies. The authors pointed out that there are many uncertainties involved in building retrofit, such as climate change, service strategy, government policies, and system interaction between retrofit technologies and building systems, and other limitations and constraints, such as specific building characteristics, total budget and project targets. As such, multi-criteria decision analysis or multi-objective optimisation methods are recommended for trade-off analysis between different criteria as part of the selection process. They also highlighted the importance of criteria selection and weighting factor allocation.

Dangana et al. (2013) organised a decision-making framework for sustainable technology selection in the case of retail buildings. The framework is structured as a multi-criteria decision process, consisting of problem identification and structuring, model building and delivery, and the synthesis of the final decision. Participants were interviewed to discuss barriers, drivers and opportunities for sustainable technology selection. The information was organised into 10 broad key criteria, including cost, risk, proven success, and transferability. These criteria were associated with corresponding weights through pair-wise comparison matrices using an AHP method developed by Zaninab et al. (2013). The proposed weightings emphasised technology risks and cost as the most influencing decision criteria in green technology selection for retail buildings.

\subsection{Summary}

Green technology selection can take multiple criteria into consideration (Nelms et al. 2005; Dangana et al. 2013). Many studies stress the importance of criteria development in the decision making process (Sheikh et al. 2011; Huang et al. 2012). They suggest that the criteria should be collected comprehensively to consider economic, environmental, social and technical performance. Economic criteria mostly contain capital cost and operation and maintenance (O\&M) cost (Zainab et al. 2013; Collier et al. 2013), installation time (Zainab et al. 2013; Collier et al. 2013), payback period (Huang et al. 2005), maintenance complexity (Nelms et al. 2007; Collier et al.2013) and available incentives (Nelms et al. 2007). Environmental criteria can include consumption of resources and environmental impacts (Collier et al. 2013). The social criteria may involve organisation mission and welfare (Collier et al. 2013), human 
health and safety, and employment creation (Odhiambo and Wekesa, 2010). Green technology selection decision might also be influenced by organisational strategy and environmental certification opportunities (Richardson and Lynes, 2007; James and Card, 2012). Technical criteria may include technology efficiency (Wang et al. 2009), the complexity of implementation (Nelms et al. 2007), the service life (Odhiambo and Wekesa, 2010), safety (Huang et al. 2012) and proven success in practice (Wang et al. 2009; Collier et al. 2013). Ma et al. (2012) advocated including risk assessment as one of the essential criteria.

Since these multiple criteria are interrelated in green technology selection, researchers (Ma et al. 2012; Zainab et al. 2013; Collier et al. 2013) have recommended multi-criteria analysis or multi-objective optimisation methods facilitating trade-off analysis between these criteria. Among the MCDM methods, AHP and MAUT were commonly used in green technology selection for building applications. Wang et al. (2009) and Ma et al. (2012) showed that appropriate criteria selection and weighting factor allocation are essential when using these methods. The criteria tree is the key to the formulation of MCDM problem. Collier et al. (2013) organised the criteria consistent with sustainability represented by triple bottom line, while $\mathrm{Ma}$ et al. (2012) organised the criteria into cost, benefit and risks categories. Again, it should be mentioned that the literature on green technology selection is mostly concerned with community scale applications (Mohsen and Akash, 1997) with limited research on decisions at building scale and their particular attributes and challenges (Dangana et al. 2013).

Building upon sustainability' triple bottom line, an integrative AHP hierarchy with multiple criteria is here proposed and presented in Figure 1. The proposed criteria tree is based on existing literature findings and its structure is informed by individual criteria attributes and interrelationships (Ibáñez-Forés et al 2014; Yu et al 2015). These criteria can be quantitative and qualitative.

It should be noted that this criteria tree is suggested for a comprehensive way of evaluating and comparing green alternatives. In reality, decision makers might need to adopt fewer criteria based on their goals, limitations and availability of data. In this case, the criteria tree may be slimmed down to a simplified version. 


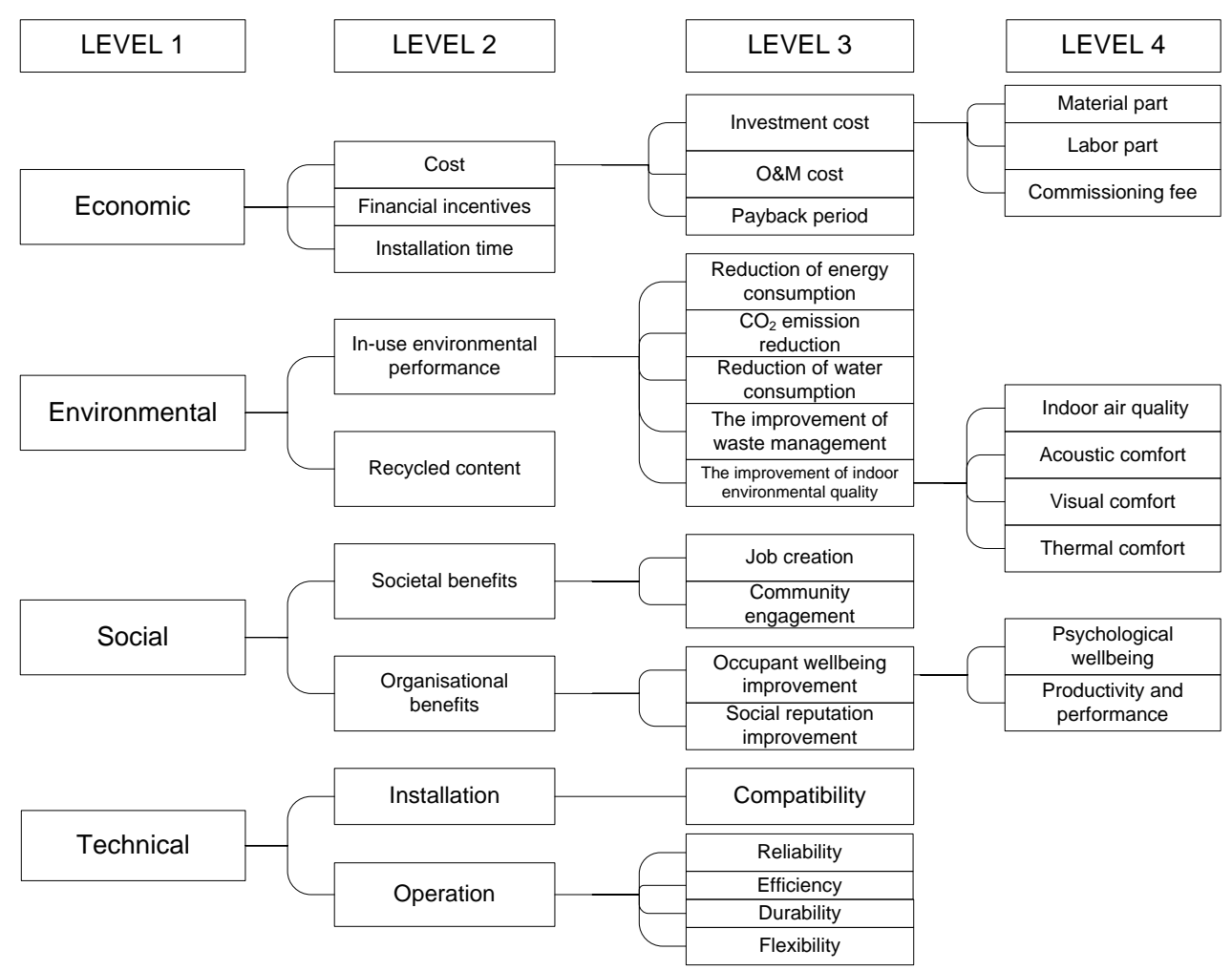

Figure 1. Integrated AHP hierarchy with multiple criteria

\section{Using MCDM for technology selection for a university building}

In order to demonstrate the applicability and usefulness of MCDM methods in formulating green technology selection decisions in existing buildings, a case study is presented. The case-study is a core University building located in central London (Figure 2). It is a typical university building for the time when it was designed at the beginning of $20^{\text {th }}$ century. Unlike new buildings, which can easily incorporate state-of-the-art energy efficient technologies to achieve current requirements in building energy efficiency, these old university buildings always have their intrinsic characteristics and perform poorly in energy efficiency.

The building has five levels including the basement. Academic staff offices are singular while research staff offices are multi-occupied. All staff offices were originally built with natural single-sided ventilation. Apart from staff offices, there are some teaching rooms and lecture theatres on the upper floors (including a video conferencing suite) and laboratories in the basement. The building opens at $8 \mathrm{am}$ with laboratories closing at $5 \mathrm{pm}$ but staff and students essentially have 24-hour access to the building.

This building was constructed in 1919 from solid stone. Further brick extension with mechanical ventilation was added in 1980s. The whole building was refurbished in 2005. During the refurbishment, the windows facing the street were replaced with double-glazing, but windows facing the campus remained single-glazed. The lighting has also been improved. The majority of the lamps were changed into T5 fluorescent tubes, with a few T8 lamps and high wattage Halogen spotlights. 
The heat and electricity for the building are supplied by a university owned Combined Heat and Power (CHP) plant. The heat in the building is supplied via a meter and distributed through radiators with thermostatic valves. All except two pumps in the building have been installed with Variable Speed Drives (VSD). Cooling is supplied via Fan Coil Units (FCU), which are manually controlled. Ventilation is provided via Air Handling Units (AHU). There are three AHUs in this building. AHU 1 and AHU 2 have been found operating the whole day with manual control. A building management system (BMS) is installed but there is a perception it does not work effectively.

The university has been working on a Carbon Management Strategy and Implementation Plan since 2008 (UCL 2008 Strategy, 2008), which is to reach a target of 10\% reduction of 2005/2006 carbon emission baseline by 2013. The 2008 Strategy has involved multiple stakeholders:

1) The Environmental Sustainability Action Group: mainly based within the Estates Division, also with stakeholder representations from other support services, Green Champions and students. Its role is to implement the university's environmental sustainability initiatives.

2) The Environmental Sustainability Steering Group: a formal consultative committee with academic, non-academic and student representations. They are responsible for wider consultation and approval of the issues reported from the Environmental Sustainability Action Group.

3) Estates Management Committee: with the President and Provost of the university as the chair, Director of Estates Division and Dean of Faculty of Social and Historical Sciences as the members. The committee is to provide oversight and strategic support to the plan development, monitor the progress of the carbon reduction against agreed targets and sign off any amendments or new strategies prior to submission to the council for approval.

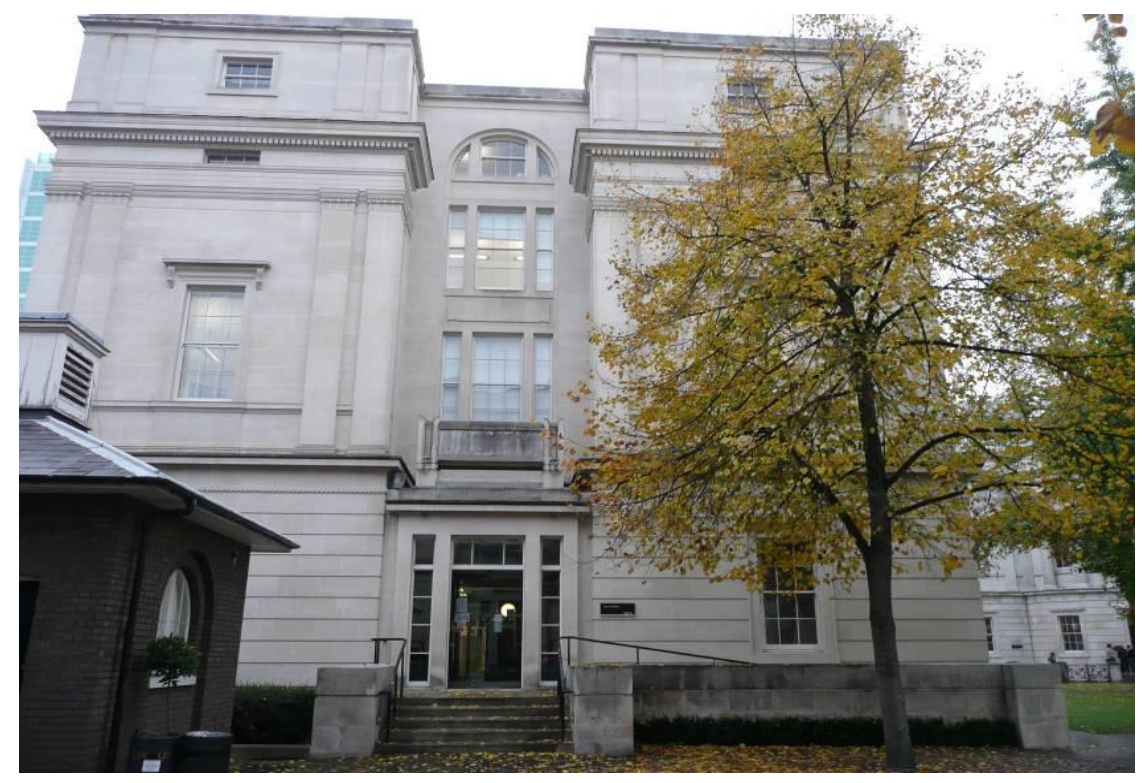

Figure 2. Case study building 
The Strategy Implementation plan identified the case study building as a show case for exploring potential solutions as well as operational problems in delivering energy efficiency improvements.

\subsection{Operational issues and technology suggestion}

The university sustainability team engaged a certified building consultancy firm to conduct an energy survey for the case building in September 2008 and propose further energy saving solutions. The current status of building services was assessed and alternative energy saving technologies were proposed for building fabric, lighting, HVAC equipment and management system as presented in Table 2 .

The building fabric is a solid construction, with no possibility of cavity wall insulation. Secondary glazing for the remaining single-glazed windows was recommended, which can improve the thermal properties of the windows and reduce noise to some extent.

As the survey revealed that the stairwells lights operate all day, a passive infrared sensor (PIR sensor) was suggested to install in the staircases. The PIR sensor was found in most classrooms and lecture theatres, but their sensitivity should be further improved. One lecture theatre was noticed consuming a significant amount of lighting, and would benefit from installation of a lighting timer.

Control of AHUs with night-time setback was proposed. It was suggested that the existing BMS in the building should be re-commissioned to incorporate lighting and security. As no sub-metering data are available, it was suggested that an automated monitoring and targeting (AM\&T) system be installed.

Table 2 Alternative energy saving technologies list

\begin{tabular}{|c|c|c|c|c|c|}
\hline Categories & Energy saving technologies & Code & $\begin{array}{l}\text { Annual energy } \\
\text { saving (KWh) }\end{array}$ & $\begin{array}{l}\text { Investment } \\
\text { cost }(£)\end{array}$ & $\begin{array}{c}\text { Payback } \\
\text { period } \\
(\mathrm{yrs})\end{array}$ \\
\hline Fabric & $\begin{array}{l}\text { Secondary glazing on all } \\
\text { remaining single-glazed } \\
\text { windows }\end{array}$ & C1 & 20160 & 11200 & 16 \\
\hline \multirow{3}{*}{ Lighting } & $\begin{array}{c}\text { Replacing } 50 \mathrm{~W} \text { halogen } \\
\text { spotlights with } 30 \mathrm{~W} \text { halogen } \\
\text { lamps }\end{array}$ & $\mathrm{C} 2$ & 1800 & 298 & 0.8 \\
\hline & $\begin{array}{c}\text { Passive Infrared Sensor (PIRs) } \\
\text { in stairwells }\end{array}$ & $\mathrm{C} 3$ & 1845 & 200 & 0.8 \\
\hline & Lighting timer installed in the & C4 & 1620 & 240 & 1.2 \\
\hline
\end{tabular}




\begin{tabular}{|c|c|c|c|c|c|}
\hline & lecture theatre G22 & & & & \\
\hline & $\begin{array}{l}\text { Remaining T8 lamps } \\
\text { replacement with T5 lamps }\end{array}$ & C5 & 378 & 440 & 8 \\
\hline \multirow{3}{*}{$\begin{array}{l}\text { HVAC } \\
\text { equipment }\end{array}$} & $\begin{array}{l}\text { Fitting Variable Speed Drives } \\
\text { (VSD) in AHU }\end{array}$ & C6 & 24090 & 3601 & 1.5 \\
\hline & Integrating FCU with BMS & $\mathrm{C} 7$ & 19250 & 0 & 0 \\
\hline & Temperature control on AHU & $\mathrm{C} 8$ & 8760 & 640 & 0.8 \\
\hline \multirow{2}{*}{ Management } & $\begin{array}{l}\text { Extending the monitoring } \\
\text { system to AM\&T system }\end{array}$ & C9 & 46033 & 15500 & 4.9 \\
\hline & Optimizing BMS & C10 & 18413 & 3000 & 2.4 \\
\hline
\end{tabular}

\subsection{Technology selection using MCDM method}

\subsubsection{AHP Application to the case study building}

Available information from a consultancy report summarised in Table 2 was crossed referenced with proposed AHP hierarchy, see shaded fields in Figure 3. Due to data availability, only economic and environmental criteria are taken into account. Under economic criteria, two sub criteria of investment cost and payback period are selected. For environmental criteria, the criterion of annual energy saving has been used. No data is available for the development of social and technical criteria, regardless of the fact that the main stakeholder, the university, recognises the close link between the Carbon Management Strategy and wider sustainability agenda. The criteria tree of selected criteria (which are highlighted in blue) is shown as Figure 3.

For criteria weighting, according to Collier et al (2013), the weight values allocated to environmental, economic and social criteria in sustainability analysis are 0.7, 0.2 and 0.1 , respectively. Given that there were only two aspects of criteria, economic and environmental, considered in this case study, the energy saving potential and economic criteria were assigned with the weight values of 0.7 and 0.3 , respectively. For the sub-criteria of investment cost and payback period, weighting values were assigned as 0.6 and 0.4 . 


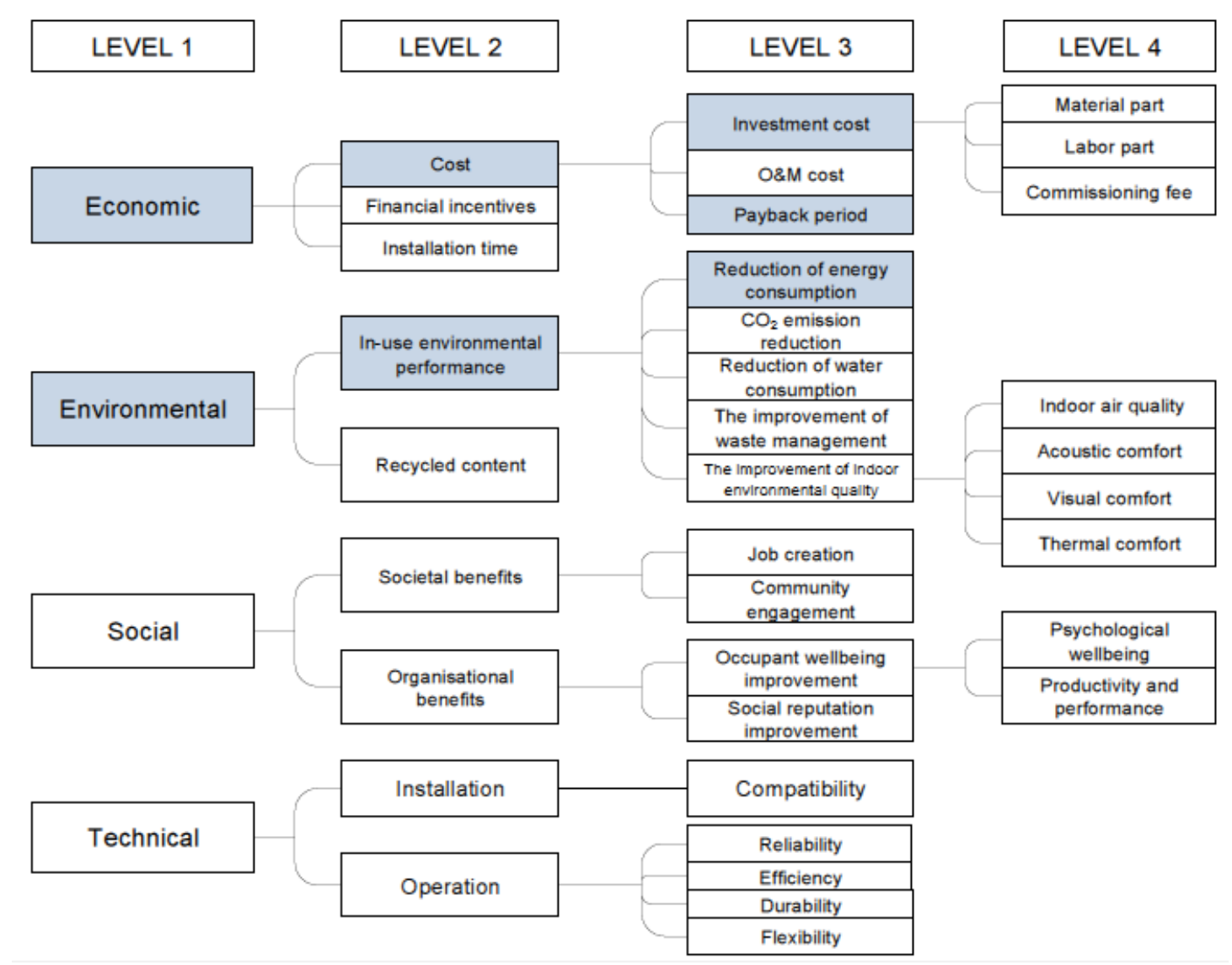

Figure 3. The AHP hierarchy for case study

The technology performance regarding individual criterion is compared in pairs, which are then converted into 1-9 scale. The consultancy firm provided data to University in relation to annual energy saving, investment cost and payback period for alternatives listed in Table 2. For example, annual energy saving of $\mathrm{C} 1$ was $20160 \mathrm{kWh} / \mathrm{yr}$, the investment cost was $£ 11200$ and the payback period was 16 years), the comparison can be directly conducted presenting the quotients (the quotient of $A$ versus $B$ is equal to value of $A$ divided by value of $B$ ). The quotient results can span over a wide numerical range. For example, the range of quotients for energy saving performance was from 1.20 to 77.50 . For the comparisons at the same level, it is essential to organise the quotients into the same scale. In doing so, we employ the relative importance (pairwise comparison) scale from 1 to 9 as developed by Satty (1990). If alternative $A$ has a greater value than alternative $B$, the pair-wise comparison of $A$ to $B$ will be greater than 1. Otherwise, the pair-wise comparison value is less than 1. In this sense, the pair-wise comparison of $\mathrm{B}$ to $\mathrm{A}$ would the reciprocal of the above value. For example, annual energy saving of alternative C6 is 8.18 times greater than $\mathrm{C} 5$. The quotient " 8.18 " is then assigned into the value of 4 according to the distribution of all the quotients for all other alternatives. For the reciprocal value on the upside of the diagonal, 1/4 is assigned, which means that $\mathrm{C} 5$ is $1 / 4$ of $\mathrm{C} 6$ in annual energy saving. Following this approach and theory presented in 2.1, the matrices of pair comparisons (MPC) can be developed for all alternatives listed in Table 2. The MPC of annual energy saving, investment cost and payback period are presented in Tables 3 to 5 respectively. The MPC of annual energy saving is 10 columns by 10 
rows. For the MPC of economic criteria, the matrices are 9 columns by 9 rows with the absence of $\mathrm{C} 7 . \mathrm{C} 7$ has no cost and zero payback period, which cannot be processed for weights calculation in MPC. In this sense, the analysis of $\mathrm{C} 7$ is carried out separately.

Table 3 Relational scoring of alternative technologies regarding annual energy saving (AES)

\begin{tabular}{ccccccccccc}
\hline & $\mathrm{C} 1$ & $\mathrm{C} 2$ & $\mathrm{C} 3$ & $\mathrm{C} 4$ & $\mathrm{C} 5$ & $\mathrm{C} 6$ & $\mathrm{C} 7$ & $\mathrm{C} 8$ & $\mathrm{C} 9$ & $\mathrm{C} 10$ \\
\hline $\mathrm{C} 1$ & 1.00 & 0.25 & 0.25 & 0.25 & 0.14 & 1.00 & 1.00 & 2.00 & 1.00 & 1.00 \\
\hline $\mathrm{C} 2$ & 4.00 & 1.00 & 1.00 & 1.00 & 0.33 & 2.00 & 3.00 & 2.00 & 5.00 & 3.00 \\
\hline $\mathrm{C} 3$ & 4.00 & 1.00 & 1.00 & 1.00 & 0.33 & 2.00 & 3.00 & 2.00 & 5.00 & 3.00 \\
\hline $\mathrm{C} 4$ & 4.00 & 1.00 & 1.00 & 1.00 & 0.33 & 4.00 & 4.00 & 2.00 & 6.00 & 3.00 \\
\hline $\mathrm{C} 5$ & 7.00 & 3.00 & 3.00 & 3.00 & 1.00 & 8.00 & 7.00 & 5.00 & 9.00 & 7.00 \\
\hline $\mathrm{C} 6$ & 1.00 & 3.00 & 0.50 & 2.00 & 0.13 & 1.00 & 1.00 & 0.50 & 1.00 & 1.00 \\
\hline $\mathrm{C} 7$ & 1.00 & 0.33 & 0.33 & 0.25 & 0.14 & 1.00 & 1.00 & 0.50 & 2.00 & 1.00 \\
\hline $\mathrm{C} 8$ & 0.50 & 0.50 & 0.50 & 0.50 & 0.20 & 2.00 & 2.00 & 1.00 & 2.00 & 1.00 \\
\hline $\mathrm{C} 9$ & 1.00 & 0.20 & 0.20 & 0.17 & 0.11 & 1.00 & 0.50 & 0.50 & 1.00 & 0.50 \\
\hline $\mathrm{C} 10$ & 1.00 & 0.33 & 0.33 & 0.33 & 0.14 & 1.00 & 1.00 & 1.00 & 2.00 & 1.00 \\
\hline
\end{tabular}

Table 4 Relational scoring of alternative technologies regarding the investment cost (IC)

\begin{tabular}{cccccccccc}
\hline & C1 & C2 & C3 & C4 & C5 & C6 & C8 & C9 & C10 \\
\hline C1 & 1.00 & 0.14 & 0.13 & 0.14 & 0.17 & 0.33 & 0.20 & 1.00 & 0.33 \\
\hline C2 & 7.00 & 1.00 & 1.00 & 1.00 & 1.00 & 5.00 & 2.00 & 8.00 & 5.00 \\
\hline C3 & 8.00 & 1.00 & 1.00 & 1.00 & 2.00 & 5.00 & 3.00 & 9.00 & 5.00 \\
\hline C4 & 7.00 & 1.00 & 1.00 & 1.00 & 2.00 & 5.00 & 3.00 & 9.00 & 5.00 \\
\hline C5 & 6.00 & 1.00 & 0.50 & 0.50 & 1.00 & 4.00 & 1.00 & 7.00 & 4.00 \\
\hline C6 & 3.00 & 0.20 & 0.20 & 0.20 & 0.25 & 1.00 & 0.25 & 3.00 & 1.00 \\
\hline C8 & 5.00 & 0.50 & 0.33 & 0.33 & 1.00 & 4.00 & 1.00 & 6.00 & 4.00 \\
\hline C9 & 1.00 & 0.13 & 0.11 & 0.11 & 0.14 & 0.33 & 0.17 & 1.00 & 0.25 \\
\hline C10 & 3.00 & 0.20 & 0.20 & 0.20 & 0.25 & 1.00 & 0.25 & 4.00 & 1.00 \\
\hline
\end{tabular}

Table 5 Relational scoring of alternative technologies regarding payback period (PP)

\begin{tabular}{cccccccccc}
\hline & $\mathrm{C} 1$ & $\mathrm{C} 2$ & $\mathrm{C} 3$ & $\mathrm{C} 4$ & $\mathrm{C} 5$ & $\mathrm{C} 6$ & $\mathrm{C} 8$ & $\mathrm{C} 9$ & $\mathrm{C} 10$ \\
\hline $\mathrm{C} 1$ & 1.00 & 9.00 & 9.00 & 8.00 & 2.00 & 7.00 & 9.00 & 3.00 & 6.00 \\
\hline $\mathrm{C} 2$ & 0.11 & 1.00 & 1.00 & 1.00 & 0.14 & 1.00 & 1.00 & 0.17 & 0.33 \\
\hline $\mathrm{C} 3$ & 0.11 & 1.00 & 1.00 & 1.00 & 0.14 & 1.00 & 1.00 & 0.17 & 0.33 \\
\hline $\mathrm{C} 4$ & 0.13 & 1.00 & 1.00 & 1.00 & 0.17 & 1.00 & 1.00 & 0.25 & 0.50 \\
\hline $\mathrm{C} 5$ & 0.50 & 7.00 & 7.00 & 6.00 & 1.00 & 5.00 & 7.00 & 1.00 & 3.00 \\
\hline $\mathrm{C} 6$ & 0.14 & 1.00 & 1.00 & 1.00 & 0.20 & 1.00 & 1.00 & 0.33 & 1.00 \\
\hline $\mathrm{C} 8$ & 0.11 & 1.00 & 1.00 & 1.00 & 0.14 & 1.00 & 1.00 & 0.17 & 0.33 \\
\hline $\mathrm{C} 9$ & 0.33 & 6.00 & 6.00 & 4.00 & 1.00 & 3.00 & 6.00 & 1.00 & 2.00 \\
\hline $\mathrm{C} 10$ & 0.17 & 3.00 & 3.00 & 2.00 & 0.33 & 1.00 & 3.00 & 0.50 & 1.00 \\
\hline & & & & & & & & &
\end{tabular}


When all the MPCs of technology performance regarding different criteria are available, the relative performance scores of each technology can be calculated (Afshari et al. 2010). With the weight values of the criteria and the technology performance scores regarding individual criterion, the integrated performance scores (IPS) of each technology were calculated using the linear additive function (5):

$$
\mathrm{V}_{i}=\sum_{i} \omega_{i} x_{i}, \text { where } \sum \omega_{i}=1
$$

where $\omega_{i}$ is the weight value of criterion $i, x_{i}$ is the corresponding technology performance scores, and $\mathrm{V}_{i}$ is the IPS calculated for criterion $i$. The global scores of technologies are calculated using the equation (6):

$$
\text { Global scores =IPS for AES +IPS for IC* + IPS for PP * }
$$

Because the impacts of investment cost and payback period are in an opposite to that of energy saving potential for the performance scores, the technology performance scores for these two criteria are generated from the transposed MPCs $\left(\mathrm{IC}^{*}\right.$ and $\mathrm{PP}^{*}$ mean transposed matrices of investment cost and payback period are used). The MPCs used in this study have all passed consistency checking. The results are shown in Table 6.

Table 6 Relative scores of alternative technologies

\begin{tabular}{ccccccccc}
\hline Code & $\begin{array}{c}\text { The score } \\
\text { for AES }\end{array}$ & $\begin{array}{c}\text { Ranking } \\
\text { for AES }\end{array}$ & $\begin{array}{c}\text { The score } \\
\text { for IC }\end{array}$ & $\begin{array}{c}\text { Ranking } \\
\text { for IC }\end{array}$ & $\begin{array}{c}\text { The } \\
\text { score for } \\
\text { PP }\end{array}$ & $\begin{array}{c}\text { Ranking } \\
\text { for PP }\end{array}$ & $\begin{array}{c}\text { Global } \\
\text { score }\end{array}$ & $\begin{array}{c}\text { Final } \\
\text { ranking }\end{array}$ \\
\hline C1 & 0.14 & 4 & 0.264 & 2 & 0.02 & 9 & 0.148 & 4 \\
\hline C2 & 0.03 & 10 & 0.030 & 7 & 0.18 & 1 & 0.048 & 7 \\
\hline C3 & 0.03 & 9 & 0.026 & 8 & 0.18 & 1 & 0.047 & 8 \\
\hline C4 & 0.03 & 8 & 0.026 & 9 & 0.16 & 4 & 0.045 & 9 \\
\hline C5 & 0.02 & 6 & 0.041 & 6 & 0.03 & 8 & 0.025 & 10 \\
\hline C6 & 0.16 & 1 & 0.133 & 3 & 0.14 & 5 & 0.153 & 3 \\
\hline C7 & 0.14 & 5 & - & - & - & - & & 1 \\
\hline C8 & 0.09 & 2 & 0.051 & 5 & 0.18 & 1 & 0.094 & 6 \\
\hline C9 & 0.22 & 7 & 0.299 & 1 & 0.04 & 7 & 0.213 & 2 \\
\hline C10 & 0.14 & 3 & 0.129 & 4 & 0.08 & 6 & 0.131 & 5 \\
\hline
\end{tabular}

The final ranking of individual technology is based on the global score. The larger the global score, the higher the ranking of the technology. On that basis, the top three technologies are listed in Table 7. C7 has the overall ranking of 1, where investment cost and payback period have the highest priority. In contrary, C6 has a better annual energy saving but lower priorities for other criteria. C9 gives the highest priority to annual energy saving but poor performance in terms of investment cost and payback period. 
Table 7 Top three ranking technologies

\begin{tabular}{cccccc}
\hline Code & Technology & $\begin{array}{c}\text { Ranking for } \\
\text { AES }\end{array}$ & $\begin{array}{c}\text { Ranking } \\
\text { for IC }\end{array}$ & $\begin{array}{c}\text { Ranking } \\
\text { for PP }\end{array}$ & $\begin{array}{c}\text { Final } \\
\text { ranking }\end{array}$ \\
\hline C7 & Integrating FCU with BMS & 5 & 1 & 1 & 1 \\
\hline C9 & $\begin{array}{c}\text { Extending the monitoring } \\
\text { system to AM\&T system }\end{array}$ & 7 & 1 & 7 & 2 \\
\hline C6 & $\begin{array}{c}\text { Fitting Variable Speed Drives } \\
\text { (VSD) in AHU }\end{array}$ & 1 & 3 & 5 & 3 \\
\hline
\end{tabular}

In contrast, less desirable technologies are listed in Table 8 that includes C3, C4 and C5. Both C3 and C4 have poor performance in annual energy saving and investment cost but have a good performance in payback period, especially for C3. C5 has a relatively good performance in both annual energy saving and investment cost but a poor performance in payback period.

Table 8 The Less desirable technologies

\begin{tabular}{cccccc}
\hline Code & Technology & $\begin{array}{c}\text { Ranking for } \\
\text { AES }\end{array}$ & $\begin{array}{c}\text { Ranking } \\
\text { for IC }\end{array}$ & $\begin{array}{c}\text { Ranking for } \\
\text { PP }\end{array}$ & $\begin{array}{c}\text { Final } \\
\text { ranking }\end{array}$ \\
\hline C3 & $\begin{array}{c}\text { Passive Infrared Sensor } \\
\text { (PIRs) in stairwells }\end{array}$ & 9 & 8 & 1 & 8 \\
\hline C4 & $\begin{array}{c}\text { Lighting timer installed in the } \\
\text { lecture theatre G22 }\end{array}$ & 8 & 9 & 4 & 9 \\
\hline C5 & $\begin{array}{c}\text { Remaining T8 lamps } \\
\text { replacement with T5 lamps }\end{array}$ & 6 & 6 & 8 & 10 \\
\hline
\end{tabular}

\subsubsection{Discussion}

The ranking results reflect the desirability of alternative technologies with respect to decision criteria. The assessment considered different priorities for decision criteria reflected by criteria weight values. It should be mentioned that the outcome would differ when the weight values are allocated differently. By changing the weight values, a sensitivity analysis can be conducted to evaluate the impacts of weight values on the overall ranking of alternatives. Moreover, considering additional decision criteria, both the overall ranks and the criteria priorities could change even if some of criteria weights remain unchanged.

The case study has been conducted based on three selection criteria considering the availability of relevant data and information. The selection and implementation of green technologies in an individual university building could be further influenced by the sustainability agenda of the university as a whole, including social criteria, such as organisation mission on sustainability (Collier et al. 2013), health and safety issues, job creation targets (Odhiambo and Wekesa, 2010). Other technical criteria such as the complexity and feasibility of technology integration in buildings (Nelms et al. 2007) and maturity and reliability of the technology (Wang et al. 2009; Collier et al. 2013) should be also involved. In this study, the 
decision makers, the sustainability team, did not include social and technical criteria in their considerations. The reasons might be the time requirements and complexity of qualitative information collection or the lack of decision-making tools aiding for qualitative assessment. Social criteria such as university reputation, education benefits or occupant satisfaction are important for a higher education building for retrofitting technology selection. Social criteria may reflect the intentions of decision makers alongside environmental, economic and technical criteria, although they were left out of the case study analysis.

\section{Conclusion and future work}

The AHP method allows a comparative assessment of options for technologies to be retrofitted to existing buildings to reduce carbon emissions and energy consumption. The method enables consideration of the influences of multiple criteria for technology selection. AHP has been employed to derive the relative performance scores for technologies. The criteria involved in the case study were annual energy saving, investment cost and payback period. Based on the weight values, the result showed that Integrating Fan Coil Units with a Building Management System, extending the monitoring system to AM\&T system, and Fitting Variable Speed Drives in Air Handling Units are preferable to other technologies.

It should be emphasised that in AHP method the hierarchy between criteria and weight value allocations are important. When more criteria are taken into consideration, the interrelations between criteria can be altered, and alternative hierarchies may influence the weights allocation. This confirms the necessity that the agreement with decision makers should be reached for the development of criteria hierarchy. Different weight values allocation will change the final ranking results. Sensitivity analysis can be conducted in this regard to identify the desirable weight values for decision makers.

Building on this work, an integrated framework of technology selection is under development aiming to further involve decision makers into decision-making process. The framework includes four phases: site and building information collection, technology listing and screening, technology evaluation with MCDM methods, as well as the integration of the final results. Following the framework, decision makers can investigate the opportunities and limitations of potential technologies application, and compare potential technologies with multiple criteria consideration before they take suggestions from technology companies. The framework can help decision makers to formulate the problem, investigate the opportunities and limitations of the building, screen out unsuitable technologies in the early stage and improve understanding for technology selection involving multiple criteria and the way that their value judgments may affect the ultimate decision results. 


\section{References}

Afshari, A., Mojahed, M., and Yusuff, R.M. (2010) 'Simple Additive Weighting approach to Personnel Selection problem'. International Journal of Innovation, Management and Technology, 1(5), pp.511-515.

Ardente, F., Beccali, M., Cellura, M., and Mistretta, M. (2011). 'Energy and environmental benefits in public buildings as a result of retrofit actions'. Renewable and Sustainable Energy Reviews, 15, pp. 460-470.

Butler, D. (2008). 'Architects of a low-energy future'. Nature, 452 (3), pp. 520-523.

Castleton, H.F., Stovin, V., Beck, S.B.M. and Davison, J.B. (2010). 'Green roofs; building energy savings and the potential for retrofit'. Energy and Buildings. 42(10), pp. 1582-1591.

Chidiac, S.E., Catania, E.J.C., Morofsky, E. and Foo, S. (2011). 'Effectiveness of single and multiple energy retrofit measures on the energy consumption of office buildings'. Energy, 36, pp. 5037-5052.

Collier, Z.A., Wang, D., Vogel, J.T., Tatham, E.K. and Linkov, I. (2013). 'Sustainable roofing technology under multiple constraints: a decision-analytical approach'. Environmental System Decision. 33(2), pp.261-271.

Dangana, Z., Pan, W. and Goohew, S. (2013). 'A decision making system for selecting sustainable technologies for retail buildings'. The 2013 CIB World Building Congress, Brisbane, Australia, 5-9 May 2013. In Energy and the Built Environment Proceedings, pp. 108-119.

Dawood, S., Crosbie, T., Dawood, N. and Lord, R. (2013). 'Designing low carbon buildings: A framework to reduce energy consumption and embed the use of renewables'. Sustainable Cities and Society, 8, 63-71

Energy Efficiency Directive (2012/27/EU) [Online]. Available at: http://ec.europa.eu/energy/en/topics/energy-efficiency/energy-efficiency-directive. (Accessed: 12 April, 2015)

Gore, C., Murray, K. and Richardson, B. (1992). Strategic Decision-making. USA: Cassell press.

Guo Y.J. System synthetical evaluation theory, methods and application. Beijing: Science Press; 2007.

Huang, B.J., Yang, H.J., Mauerhofer, V. and Guo, R.(2012). 'Sustainability assessment of low carbon technologies-case study of the building sector in China'. Journal of Cleaner Production. 32, pp.244-250.

Huang, F. Y., Wu, J.Y., Wang, R.Z., and Huang, X.H. (2005). 'Study on comprehensive evaluation model for combined cooling heating and power system (CCHP)'. Journal of Engineering Thermophysics.26, pp.6-13.

Ibáñez-Forés, V., Bovea, M.D. \& Pérez-Belis, V. (2014). 'A holistic review of applied methodologies for assessing and selecting the optimal technological alternative from a sustainability perspective'. Journal of Cleaner Production, 70, pp.259-281.

James, M. and Card, K. (2012). 'Factors contributing to institutions achieving g environmental sustainability'. International Journal of Sustainability in Higher Education. 13(2), pp. 166-176. Konidari, P. and Mavrakis, D. (2007). 'A multi-criteria evaluation method for climate change mitigation policy instruments'. Energy Policy, 35(12), 6235-6257. 
Linkov, I. and Moberg, E. (2012). Multi-criteria Decision Analysis: Environmental Applications And Case Studies. USA: CRC Press.

Linkov, I. and Ramadan, A.B.(2004). Comparative Risk Assessment and Environmental Decision making. Springer Science \& Business Media.

Løken, E (2007). 'Use of multi-criteria decision analysis methods of energy planning problems'. Renewable and Sustainable Energy reviews. 11, pp. 1584-1595.

Ma, Z., Cooper, P., Daly, D., \& Ledo, L. (2012). 'Existing building retrofits: Methodology and state-of-the-art'. Energy and Buildings.55.pp. 889-902

Mafakheri, F., Dai, L., Slezak, D., \& Nasiri, F. (2007). 'Project Delivery System Selection under Uncertainty: Multi-criteria Multilevel Decision Aid Model'. Journal of Management in Engineering, 23(4), 200-206.

Nelms,C., Russell,A.D. and Lence, B.J. (2005). 'Assessing the performance of sustainable technologies for building projects'. Canadian Journal of Civil Engineering. 32(1), pp.114-128.

Nelms, C., Russell,A.D., and Lence, B.J. (2007). 'Assessing the performance of sustainable technologies: a framework and its application Building research and information.' Building Research \& Information. 35(3), pp. 237-251.

Norris, M. and Shiels, P. (2004). Regular national report on housing developments in European countries-synthesis report. Dublin: The Housing Unit.

Odhiambo, J. and Wekesa, B. (2010). 'A framework for assessing building technologies for marginalised communities', Human Settlements Review, 1, pp. 59-85

Pan, W., Adrew, R.J., Dainty, M. ASCE and Alistair,G.F.G. (2012). 'Establishing and weighting decision criteria for building system selection in housing construction'. Journal of construction engineering and management. 138, pp. 1239-1250.

Papadatos, N. and Xifara,T. (2013). 'A simple method for obtaining the maximal correlation coefficient and related characterizations'. Journal of Multivariate Analysis. 118, pp.102-114.

Pirlot, M. (1997). 'A common Framework for Describing Some Outranking Methods.' Journal of Multi-Criteria Decision Analysis. 6, pp. 86-92.

Pérez-Lombard, L., Ortiz, J., and Pout, C. (2008). 'A review on buildings energy consumption information'. Energy and Buildings, 40(3), 394-398.

Pohekar, S.D. and Ramachandran, M.(2004). 'Application of multi-criteria decision making to sustainable energy planning-A review'. Renewable and Sustainable Energy Reviews. 8(4), pp. $365-381$

Richardson, G.R.A. and Lynes, J.K. (2007). 'Institutional motivations and barriers to the construction of green buildings on campus'. International Journal of Sustainability in Higher Education. 8(3),pp. 339-354.

Roberts, S. (2008). 'Altering existing buildings in the UK'. Energy Policy, 36(12), pp.44824486.

Rowe, G. and Wright, G. (2001) Expert opinions in forecasting: role of the delphi technique. Armstrong (Ed.), Principles of forecasting: a handbook of researchers and practitioners, Kluwer Academic Publishers, Boston.

Saidur, R (2009). 'Energy consumption, energy savings, and emission analysis in Malaysian office buildings'. Energy Policy, 37 (10),pp. 4104-4113

Satty, T.L.(1990). 'How to make a decision: The analytic hierarchy process.' European Journal 
of Operational Research. 48(1),pp.9-26.

Saaty, T. L.(2000). 'Fundamentals of decision making and priority theory with the analytic hierarchy process'. RWS, Pittsburgh.

Sheikh, N. and Kocaoglu, D,F. (2011). 'A comprehensive assessment of solar photovoltaic technologies: literature review'. Technology Management in the Energy Smart World (PICMET), Portland. July31,-Aug.4,2011.

Sheikh,N., Daim, T. and Kocaoglu. D, F. (2011) 'Use of multiple perspectives and decision modeling for PV technology assessment.'Technology Management in the Energy Smart World (PICMET), Portland. July,31-Aug.4,2011.

Spyropoulos, G. N. and Balaras, C. A. (2011). 'Energy consumption and the potential of energy savings in Hellenic office buildings used as bank branches-a case study'. Energy and Buildings, 43, pp.770-778

Sutter, C. (2003). Sustainability Check-Up for CDM Projects: how to assess the sustainability of international projects under Kyoto Protocol. PhD thesis. Swiss Federal Institute of Technology Zurich. Energy \& Climate, Zurich, Switzerland.

Ürge-Vorsatz, D. and Novikova, A. (2008). 'Potentials and costs of carbon dioxide mitigation in the world's buildings'. Energy Policy, 36, pp. 642-661.

UNEP-SBCI (2009), Buildings and Climate Change, Summary for Decision-Makers. [Online]. Available at: http://www.unep.org/sbci/pdfs/SBCI-BCCSummary.pdf (Accessed June 21, 2015)

Wang J.J., Jing, Y.Y. and Zhang, C.F. (2009). 'Weighting methodologies in multi-criteria evaluations of combined heat and power systems', International journal of energy research. 33 , pp.1023-1039

Wang J.J., Jing, Y.Y., Zhang, C.F. and Zhao, J.H. (2009). 'Review on multi-criteria decision analysis aid in sustainable energy decision-making'. Renewable and Sustainable Energy Reviews. 13(9), pp.2263-2278.

Ye Y.C., Ke L.H., Huang D.Y. (2006). 'System synthetical evaluation technology and its application'. Beijing: Metallurgical Industry Press.

Yu, W., Li, B.Z., Yang, X.C. and Wang, Q.Q. (2015). 'A development of a rating method and weighting system for green store buildings in China'. Renewable Energy, 73, pp.123-129.

Zainab,S., Pan,W., Goodhew, S., and Fuertes,A. (2013). 'Stakeholders perspective on sustainable technology selection to achieve zero carbon retail buildings' [Online]. Available at: http://www.arcom.ac.uk/-docs/proceedings/ar2013-1219

1229_Zainab_Pan_Goodhew_Fuertes.pdf (Accessed: 21 October, 2014).

Zardari, N.H., Ahmed, K., Shirazi, S.M., and Yusop, Z.B.(2015) Weighting Methods and their effects on Multi-Criteria Decision Making Model Outcomes in Water Resources Management. USA: Springer Press. 